\title{
Corporate Sponsorship of the 2008, 2012, and 2016 Summer Olympics: A Test of Market Efficiency
}

\author{
Frank W. Bacon \\ Longwood University \\ Joshua A. Hutchinson \\ Longwood University
}

Corporate sponsorship is a form of advertising that companies pay to be associated with certain events. Firms with corporate sponsorships of an event such as the Olympic Games can maximize stockholder wealth by evaluating the returns on these investments. In order to evaluate the returns on these investment decisions, this study employs an event study methodology in the finance literature. Using the risk-adjusted event study methodology, this study tests the hypothesis that the risk-adjusted rates of return on the sponsor companies' stock prices are significantly positively affected by this type of information. The event study tested the effect of the 2008 Beijing, 2012 London and 2016 Rio Summer Olympic games on the sponsor company's stock prices. The opening ceremonies took place on August $8^{\text {th }}, 2008$, July $27^{\text {th }}, 2012$ and August $5^{\text {th }}$, 2016. Results for all 3 summer Olympic games and the combined global sample show positive gains to their risk-adjusted rates of return of stock prices leading to the opening ceremony, with small gains following the opening ceremony. The evidence also supports the semi-strong form of market efficiency. No investor was able to make an above normal return by acting on the event.

Keyword: market efficiency, corporate sponsorship, Summer Olympics

\section{INTRODUCTION}

This study tests market efficiency by analyzing the 2008, 2012, and 2016 Summer Olympics' impact on the risk adjusted rates of return of the sponsoring firms. The opening ceremonies' event dates were August $8^{\text {th }}, 2008$, July $27^{\text {th }}, 2012$ and August $5^{\text {th }}, 2016$, respectively. The Olympics opening ceremony date is significant because such global exposure should generate positive marketing of the sponsor's brand thereby generating the expected favorable risk adjusted rates of return of the sponsoring firm's stock price. The two most popular and longest standing sponsors of the Olympics are McDonald's and Coca-Cola. The 2008, 2012, and 2016 Olympic games all lasted 16 days. This 16-day period allows the sponsoring firms to engage powerful marketing campaigns to elevate and show off their brands. It follows that such intense advertising and messaging on a global scale should promote positive sales and cash flows thereby stimulating an increase in the firms' underlying stock prices. In order to measure the impact of the Olympic Games on the sponsoring firms' risk adjusted rates of return of stock prices, the study employs the standard event study methodology from the finance literature (Baim \& others, 2016). 


\section{PROBLEM AND PURPOSE}

How will stock prices of firms react to the opening ceremonies of the 2008, 2012 and 2016 Summer Olympics? How quickly does the market price react to these events on the day of opening ceremonies?

The purpose of this study is to test market efficiency by studying how stocks' risk adjusted rates of return react to the opening ceremonies of the 2008, 2012, and 2016 Summer Olympics. Three samples of 15 firms for each of 2008, 2012 and 2016 Summer Olympics are tested using the standard risk adjusted event study methodology from the finance literature. Market efficiency is tested by examining the risk adjusted rates of return of firms in each sample up to 30 days before and 30 days after the opening ceremonies for the 2008, 2012, and 2016 Summer Olympics with a hypothesized positive reaction. Likewise, the risk adjusted rates of return for the combined, global sample of 45 firms is analyzed up to 30 days before and 30 days after the opening ceremonies for the 2008, 2012, and 2016, Summer Olympics with an expected positive reaction. Market efficiency is tested to see if the market exhibits weak, semistrong, or strong form efficiency by examining how fast the market responds to these events over the 60day event period.

\section{LITERATURE REVIEW}

The primary goal of finance is the maximization of stockholder wealth. To achieve this goal, firms make positive net present value investment and financing decisions that cause the firm's stock price to rise thereby increasing stockholder wealth. This study focuses on the firm's sponsorship of the Olympic Games which is a significant investment in marketing the corporation's brand. The investment aims to elevate the brand by increasing the exposure and popularity of the firm's products and services on a global scale. If the investment generates increased future sales and cash flows that equate a positive net present value, then the firm's stock price will rise causing an increase in stockholder wealth. If the investment does not bring about increased future sales and cash flows, then a negative net present value results and the firm's stock price falls along with stockholder wealth.

Does the Olympic Games sponsorship investment decision increase or decrease stockholder wealth and the value of the firm? Specifically, how will stock prices of the sponsoring firms react to the opening ceremonies' event dates of the 2008, 2012, and 2016 Summer Olympics (Clarey \& others, 2016)? Are the sponsorship investment decisions viewed positively or negatively by the market (O'Connell, 2016)? Since substantial stockholder resources are employed by these sponsorship investments, evidence on the market's reaction is critical to policy makers and corporate management in aligning the firm's actions with the primary goal of maximization of stockholder wealth. In order the examine the market's reaction to the firms' sponsorship investment decisions, this research uses the standard event study methodology in the finance literature with the opening ceremonies' date as the event date. Evidence shows a positive market reaction to the sponsorship investment decision prior to the event date (Bacon \& Thompson, 2009).

Another important research question concerning market efficiency also arises. How quickly does the market price react to these events on the day of opening ceremonies? Is it possible for an investor to earn an above normal profit by acting on the event information (Beaver, 1981)? "An efficient capital market is one in which stock prices fully reflect all information available to investors" (Ross, 2016). In an efficient market, information is reflected in prices immediately so investors should only expect to gain the normal rate of return (Ross, 2016)

Fama (1970) defines three forms of market efficiency: weak form efficiency, semi-strong form efficiency, and strong form efficiency. According to the weak form market efficiency hypothesis, no investors can earn above normal risk adjusted returns based on past information such stockholder annual reports and past trends in stock price (Fama, 1970; Jensen 1978). Stock price reacts to information which arrives randomly. Therefore, stock price moves in a random pattern which is supported by the weak form efficient market hypothesis. Numerous studies (Fama, 1965; Fama \& Blume, 1966; Levy 1967) support the

Random walk theory in support of weak form efficiency claiming that historical trends are not able to predict future stock price. If the market is semi-strong form efficient, no investor can earn an above normal 
risk adjusted return by acting on public information (Fama, $1970 \&$ 1997; Bacon \& Greis, 2008; Jensen, 1978). For example, investors should not be able to earn excess returns on the public announcement of stock splits, dividend increases, dividend reductions, stock repurchases, and new stock issues because the market reacts too fast and efficiently (Mcnichols \& Dravid, 1990). The strong form efficient market hypothesis states that the market reacts to all information, public and private, so fast that no investor can earn an above normal risk adjusted return by acting this type of information (Fama, 1970; Bacon \& Spradlin, 2019). If this is true, insider trading on private information would not even result in excess returns (Finnerty, 1976). Understandably, there is little evidence to support strong form efficiency (Rozeff \& Zaman, 1988).

This study tests the semi-strong market efficiency theory by using the standard event study methodology in the finance literature (Bacon \& Greis, 2008; Bacon \& Gobran 2017; Bacon \& Cannon, 2018; and Bacon \& Spradlin, 2019). If the market is semi-strong form efficient, then two popular stock investment analysis methods are rendered useless. Investors pay analysts billions of dollars annually for this type of investment advice. But if the market is efficient, these investors are wasting billions of dollars on useless investment advice. Efforts to determine the "right" value of stock are useless if the market is semi-strong form efficient since the "right" price is the market price that instantly impounds all available and relevant information (Bacon \& Cannon, 2018)

The first valuation method in the finance investment literature called into question by the efficient market hypothesis is technical stock analysis. Technical stock analysis bases buy and sell decisions on historical stock price trends identified by charts. These chartists closely examine historical stock prices, the effect of supply and demand on stock price, popular opinions, and moods (Levy, 1966). The other popular investment analysis model used to determine stock value is fundamental stock analysis. Fundamental stock analysis estimates a stock's intrinsic value, which is the present value of expected future cash flows of the firm. Therefore, value and future cash flow depend upon the firm's earning potential, economic variables, and financial factors that cause actual market prices to move toward intrinsic values (Levy, 1966). If the fundamental intrinsic value is below the market value, the analyst recommends a sell signal and the opposite for a buy signal when the intrinsic value is above the market value. If the market is semi-strong form efficient, investors are wasting billions of dollars on technical and fundamental analyst fees for worthless advice (Bacon \& Cannon, 2018).

If the market is semi-strong form efficient, then no investor should be able to earn an above normal risk adjusted return on Olympics' opening ceremony's event date. If an above normal risk adjusted return is observed around the event date from day -30 to day +30 , then the market viewed the firm's sponsorship investment positively with a positive net present value, thus increasing the value of the firm. The study results largely support both of these hypotheses.

\section{DATA AND METHODOLOGY}

This study tests for semi-strong form market efficiency using the standard risk adjusted event study methodology in the finance literature. The study randomly selected three samples of 15 stocks each for the 2008, 201,2 and 2016 Summer Olympics from firms that trade on the NYSE. Using event study methodology, this research shows how quickly the risk adjusted rate of return of the stock prices of the total sample of 45 firms reacted to the opening ceremonies of the games. The study sample includes companies who made an investment in sponsorship of the 2008, 2012, and 2016 Summer Olympics. Tables 1, 2, and 3 show the description of the Summer Olympics Sponsor Company Samples for the 2008, 2012, and 2016, respectively. 
TABLE 1

DESCIRPTION OF 2008 SUMMER OLYMPICS SPONSOR COMPANIES SAMPLE

\begin{tabular}{|c|c|c|}
\hline Stock Symbol & Firm Name & Market Cap \\
\hline KO & Coca-Cola Co. & 208.016 B \\
\hline MCD & McDonald's Corp. & 141.763 B \\
\hline NKE & Nike & 399.599B \\
\hline INTC & Intel Corporation & $216.562 \mathrm{~B}$ \\
\hline BAC & Bank of America Corp. & 270.479B \\
\hline JNJ & Johnson and Johnson & 358.728B \\
\hline BBD & Banco Bradesco & $70.781 B$ \\
\hline BP & BP P.I.C. & 146.106B \\
\hline DFS & Discover Financial Services & 25.312B \\
\hline MSFT & Microsoft & $1.016 \mathrm{~T}$ \\
\hline MFC & Manulife & 34.854B \\
\hline SNP & China Petroleum and Chemical Corp & 82.913 B \\
\hline BHP & BHP Group & 209.642B \\
\hline TM & Toyota Motor Corporation & $175.918 \mathrm{~B}$ \\
\hline GE & General Electric & 91.112B \\
\hline
\end{tabular}

TABLE 2

DESCRIPTION OF 2012 SUMMER OLYMPICS SPONSOR COMPANIES SAMPLE

\begin{tabular}{|c|c|c|}
\hline Stock Symbol & Firm Name & Market Cap \\
\hline KO & Coca-Cola Co. & 208.016 B \\
\hline GE & General Electric Co. & $65.932 \mathrm{~B}$ \\
\hline MCD & McDonald's Corp. & $141.763 \mathrm{~B}$ \\
\hline $\mathbf{B P}$ & BP P.I.C. & 148.106B \\
\hline ACER & ACER Therapeutics & $34.562 \mathrm{~B}$ \\
\hline TM & Toyota Motor Corporation & $175.918 \mathrm{~B}$ \\
\hline $\mathbf{V}$ & Visa Inc. & 299.987 B \\
\hline PG & The Proctor and Gamble Company & 229.06 B \\
\hline NKE & NIKE, Inc. & $115.471 \mathrm{~B}$ \\
\hline $\mathbf{K}$ & Kellogg's Company & 21.342 B \\
\hline BAC & Bank of America Corp. & 270.479B \\
\hline BUD & Anheuser-Busch & 172.675B \\
\hline UPS & United Parcel Service Inc. & 97.522B \\
\hline NSANY & Nissan & 26.93B \\
\hline DFS & Discover Financial Services & 25.312B \\
\hline
\end{tabular}


TABLE 3

DESCRIPTION OF 2016 SUMMER OLYMPICS SPONSOR COMPANIES SAMPLE

\begin{tabular}{|l|l|l|}
\hline Stock Symbol & Firm Name & Market Cap \\
\hline KO & Coca-Cola Co. & 208.016 B \\
\hline GE & General Electric Co. & 65.932 B \\
\hline MCD & McDonald's Corp. & 141.763 B \\
\hline BABA & Alibaba Group Holding Limited & 401.247 B \\
\hline INTC & Intel Corporation & 216.562 B \\
\hline TM & Toyota Motor Corporation & 175.918 B \\
\hline V & Visa Inc. & 299.987 B \\
\hline PG & The Proctor and Gamble Company & 229.06 B \\
\hline NKE & NIKE, Inc. & 115.471 B \\
\hline K & Kellogg's Company & 21.342 B \\
\hline BAC & Bank of America Corp. & $270.479 B$ \\
\hline BUD & Anheuser-Busch & $172.675 B$ \\
\hline UPS & United Parcel Service Inc. & $\mathbf{9 7 . 5 2 2 B}$ \\
\hline JNJ & Johnson and Johnson & $358.728 B$ \\
\hline MFC & Manulife & $34.854 B$ \\
\hline
\end{tabular}

In order to test the semi-strong market efficiency of the Olympic Games and to show the effects of the event on stock returns on the opening ceremony dates for the 2008, 2012, and 2016 summer Olympics, the following null and alternate were employed:

H10: The risk adjusted rate of return of the stock price of the 2008 Summer Olympics sample is not significantly positively affected by this type of information on the event date.

H1 ${ }_{1}:$ The risk adjusted rate of return of the stock price of the 2008 Summer Olympics sample is significantly positively affected by this type of information on the event date.

H20: The risk adjusted rate of return of the stock price of the 2008 Summer Olympics sample is not significantly positively affected by this type of information around the event date as defined by the event period.

H2 ${ }_{1}:$ The risk adjusted rate of return of the stock price of the 2008 Summer Olympics sample is significantly positively affected by this type of information around the event date as defined by the event period.

H30: The risk adjusted rate of return of the stock price of the 2012 Summer Olympics sample is not significantly positively affected by this type of information on the event date.

$\boldsymbol{H 3}_{1}$ : The risk adjusted rate of return of the stock price of the 2012 Summer Olympics sample is significantly positively affected by this type of information on the event date.

H40: The risk adjusted rate of return of the stock price of the 2012 Summer Olympics sample is not significantly positively affected by this type of information around the event date as defined by the event period. 
H4 ${ }_{1}$ : The risk adjusted rate of return of the stock price of the 2012 Summer Olympics sample is significantly positively affected by this type of information around the event date as defined by the event period.

H50: The risk adjusted rate of return of the stock price of the 2016 Summer Olympics sample is not significantly positively affected by this type of information on the event date.

$\mathrm{H5}_{1}$ : The risk adjusted rate of return of the stock price of the 2016 Summer Olympics sample is significantly positively affected by this type of information on the event date.

H6: The risk adjusted rate of return of the stock price of the 2016 Summer Olympics sample is not significantly positively affected by this type of information around the event date as defined by the event period.

H6: The risk adjusted rate of return of the stock price of the 2016 Summer Olympics sample is significantly positively affected by this type of information around the event date as defined by the event period.

H70: The risk adjusted rate of return of the stock price of the global Summer Olympics sample including all 45 firms is not significantly positively affected by this type of information on the event date.

H71: The risk adjusted rate of return of the stock price of the of the global Summer Olympics sample including all 45 firms is significantly positively affected by this type of information on the event date.

H8:: The risk adjusted rate of return of the stock price of the global Summer Olympics sample including all 45 firms is not significantly positively affected by this type of information around the event date.

H8: The risk adjusted rate of return of the stock price of the of the global Summer Olympics sample including all 45 firms is significantly positively affected by this type of information around the event date.

For this study, all of the stock return information for the 3 samples and the S\&P 500 over the event period was collected from Yahoo! Finance. The Olympic Games Opening Ceremony date represents day 0 in the analysis. The final analysis was conducted by:

1. Obtaining the historical stock prices of the sample firms and S\&P 500 Index for the event study duration of -180 days to +30 days. The event period is defined as day -30 to +30 , with day 0 being the opening ceremony date.

2. Holding period returns of the $S \& P 500$ Index $\left(R_{M}\right)$, and the sample firms $(R)$ were calculated for each day of the study using the following formula:

\section{Current Daily Return= $\underline{\text { (current day close price- } \text { previous day close price })}$ previous day close price}

3. Using the holding period returns, a regression analysis was performed for each sample firm with the actual daily return for each company as the dependent variable and regressing it on the corresponding S\&P 500 Index, the independent variable. The regression was performed over the pre-event period (day -180 to -30) to obtain the intercept, alpha, and the standardized coefficient, beta, for each firm. Tables 4,5 , and 6 below shows alphas and betas for each firm for the 2008, 2012, and 2016 Olympic Games samples, respectively. 
TABLE 4

2008 SPONSOR COMPANIES' ALPHAS AND BETAS

\begin{tabular}{|l|l|l|}
\hline Stock Symbol & Alpha & Beta \\
\hline KO & -0.0004798 & 0.44913722 \\
\hline MCD & 0.00036647 & 0.58422242 \\
\hline NKE & 0.00063654 & 0.99237053 \\
\hline INTC & 0.00030015 & 1.47778663 \\
\hline BAC & -0.0018756 & 1.57537729 \\
\hline JNJ & $4.9435 \mathrm{E}-05$ & 0.33195712 \\
\hline BBD & 0.00175056 & 1.47510725 \\
\hline BP & 0.00029712 & 0.56219515 \\
\hline DFS & 0.00098035 & 2.36490706 \\
\hline MSFT & -0.0005992 & 0.93387684 \\
\hline MFC & $3.6209 \mathrm{E}-05$ & 0.8545697 \\
\hline SNP & -0.0008463 & 1.46552528 \\
\hline BHP & 0.00195754 & 1.17718915 \\
\hline TM & -0.0001382 & 0.90425252 \\
\hline GE & -0.0012804 & 1.09300593 \\
\hline
\end{tabular}

TABLE 5

2012 SPONSOR COMPANIES' ALPHAS AND BETAS

\begin{tabular}{|l|l|l|}
\hline Stock Symbol & Alpha & Beta \\
\hline KO & 0.0007486 & 0.53618398 \\
\hline GE & 0.00097142 & 1.105756 \\
\hline MCD & -0.0004614 & 0.50010528 \\
\hline BP & -0.00095279 & 1.194401466 \\
\hline ACER & -0.00415 & 0.662405 \\
\hline TM & 0.00092724 & 0.70760968 \\
\hline V & 0.00140268 & 0.86061014 \\
\hline PG & $-9.999 E-05$ & 0.45928076 \\
\hline NKE & 0.00068176 & 0.78942447 \\
\hline K & -0.0001714 & 0.32452596 \\
\hline BAC & 0.00078595 & 1.99093119 \\
\hline BUD & 0.00152847 & 0.88747265 \\
\hline UPS & 0.00046052 & 0.80279804 \\
\hline NSANY & $-4.439 E-05$ & 0.99182916 \\
\hline DFS & 0.00156042 & 1.19810766 \\
\hline & & \\
\hline
\end{tabular}


TABLE 6

2016 SPONSOR COMPANIES' ALPHAS AND BETAS

\begin{tabular}{|l|l|l|}
\hline Stock Symbol & Alpha & Beta \\
\hline KO & 0.00059067 & 0.53670306 \\
\hline GE & 0.00018202 & 0.90760805 \\
\hline MCD & 0.00065256 & 0.54008613 \\
\hline BABA & $4.52 \mathrm{E}-06$ & 1.25549845 \\
\hline INTC & $6.0876 \mathrm{E}-06$ & 1.20160009 \\
\hline TM & -0.0006329 & 1.06880364 \\
\hline V & -0.0002172 & 1.29234805 \\
\hline PG & 0.00078113 & 0.56497957 \\
\hline NKE & -0.0008476 & 0.87093905 \\
\hline K & 0.00117719 & 0.45188824 \\
\hline BAC & -0.001579 & 1.75999481 \\
\hline BUD & 0.0005212 & 0.01589903 \\
\hline UPS & 0.000231 & 0.70951026 \\
\hline JNJ & 0.00099693 & 0.6452693 \\
\hline MFC & -0.0003263 & -0.0236421 \\
\hline
\end{tabular}

4. To calculate the normal expected returns, the risk-adjusted method (market model) was used. The expected returns for each stock, for each day of the event period was calculated using the formula:

\section{$\mathbf{E}(\mathbf{R})=\operatorname{alpha}+\operatorname{Beta}\left(\mathbf{R}_{\mathbf{m}}\right)$}

5. Then, the excess return was calculated as:

\section{$\mathbf{E R}=$ actual return $-\mathbf{E}(\mathbf{R})$}

6. Average Excess Returns was found for each day by averaging the Excess Returns for each firm on a given day.

\section{AER= Sum of Excess Returns/N}

$\mathrm{N}=$ number of sample firms

7. In addition, cumulative AER was calculated by adding the AERs for each day of the event period, days -30 to +30 .

8. For the event period, graphs of AER and CAER were plotted to show their movement over time. Figures 1, 2, 3, and 4 below display the Average Excess Returns and the Cumulative Average Excess Returns plotted against time over the event period for the 2008, 2012, and 2016 Olympic Games samples and the global sample.

\section{QUANTITATIVE TESTS AND RESULTS}

Were the risk-adjusted stocks price returns of the 45 companies that sponsored the 2008, 2012, and 2016 Summer Olympic Games positively affected by the global event? How did the market react to the opening ceremonies on August 8th, 2008, July 27th, 2012 and August 5th, 2016? Was the information surrounding the event significant? If the information surrounding the event was significant, a substantial 
difference between the Actual Average Daily Returns (Day -30 to Day +30) and the Expected Average Daily Returns (Day -30 to +30) should be observed. In order to test for a significant difference between the Actual Average Daily Returns and the Expected Average Daily Returns, a paired sample t-test was conducted for the 2008, 2012, and 2016 Summer Olympic Game samples and the global sample. For all four samples, the evidence from the paired sample t-tests supports a significant difference between the Actual Average Daily Returns and the risk-adjusted Average Expected Daily Returns at the 5\% significance level. These results support the alternate hypotheses $\mathbf{H 2}_{\mathbf{1}}, \mathbf{H 4}_{\mathbf{1}}, \mathbf{H 6}_{\mathbf{1}}$, and $\mathbf{H 8 _ { 1 }}$ for the four samples, respectively: the risk adjusted rate of return of the stock price of the sample firms is significantly positively affected by the opening ceremonies on August 8th, 2008, July 27th, 2012 and August 5th, 2016 around the event date as defined by the event period. Because a significant market reaction was observed, the information surrounding the event date impacted stock price, resulting in a significant positive reaction to the opening ceremonies' event dates.

It is also important to determine how fast the market reacted to the Olympics event to assess the level of efficiency of the market response. Basically, did the market display weak, semi-strong, or strong form market efficiency? Specifically, are the Average Excess Returns (AERs) and the Cumulative Average Excess Returns (CAERs) for the four samples of stock significantly different than zero. T-tests of AER and CAER for the all four samples indicated a difference at the 5\% significance level. Observation of AER and CAER over the event period for Figures 1, 2, 3, and 4 shows a significant positive reaction of the risk adjusted returns of the stock prices of the four samples prior to the opening ceremony event date.

When analyzing the CAER over the event period in Figures 1,2,3, and 4 below, the goal is to determine how fast the market reacted to the event. According to Figure 1, there is an increase from day -24 to day 0 and after day 0 , the returns leveled off. In Figure 2, CAER increases commence on day -12 , then they level off from day -10 to day -5 before gradually decreasing back down until day +12 . Figure 3 shows CAER was positive from day -30 to -14 , then leveled off until day 0 and after day 0 returns were positive. In figure 4 (global sample) evidence shows an increase in CAER up to 27 days prior to event date (day 0), but then staying constant for the duration of the Games. In all four Olympic games samples, excess returns peaked prior to the event date. Therefore, evidence shows that the market had already imbedded the corporate sponsorship information into the stock prices of the sponsor companies prior to the event dates of August 8th, 2008, July 27th, 2012 and August 5th, 2016, thus supporting semi-strong form efficiency. Since the market already responded prior to the event date, no investor could earn an above normal risk adjusted rate of return on the event date.

FIGURE 1

AER \& CAER OF 2008 SPONSORS

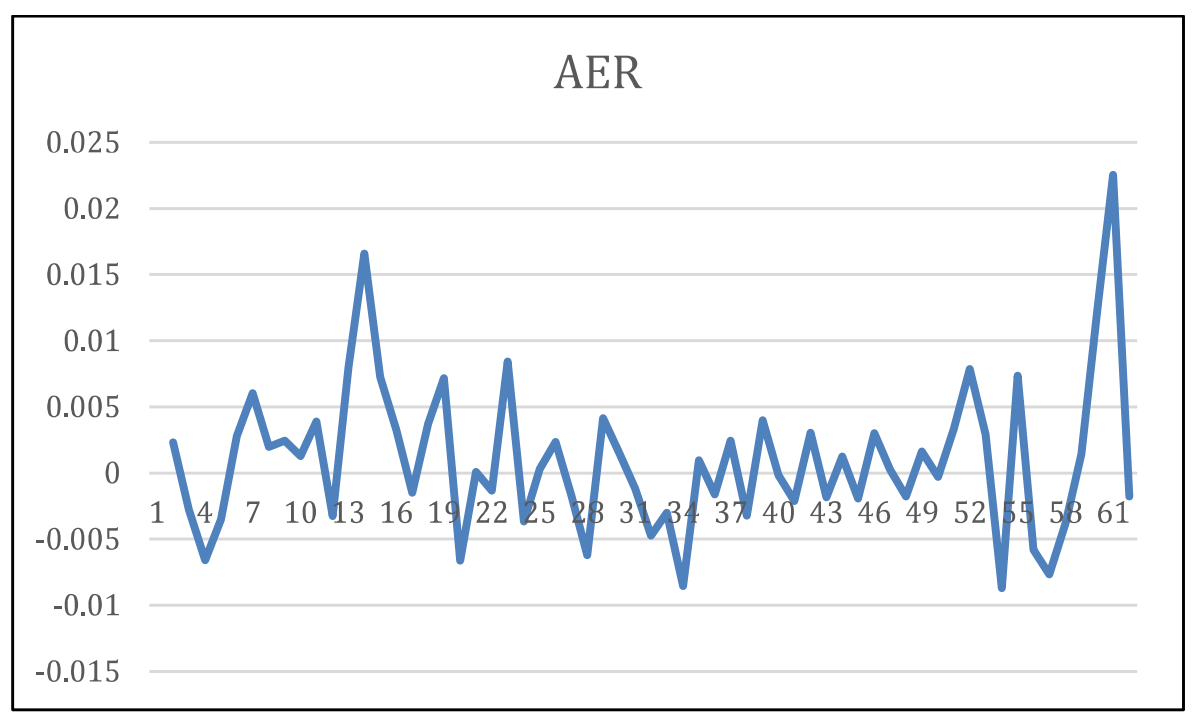




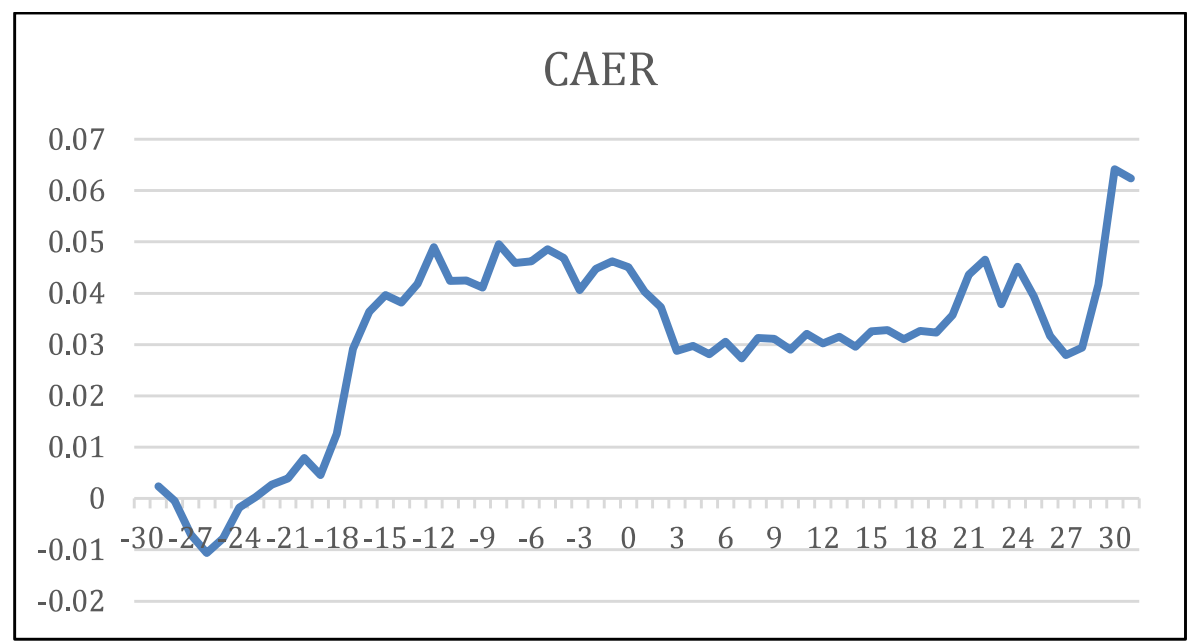

FIGURE 2

AER \& CAER OF 2012 SPONSORS

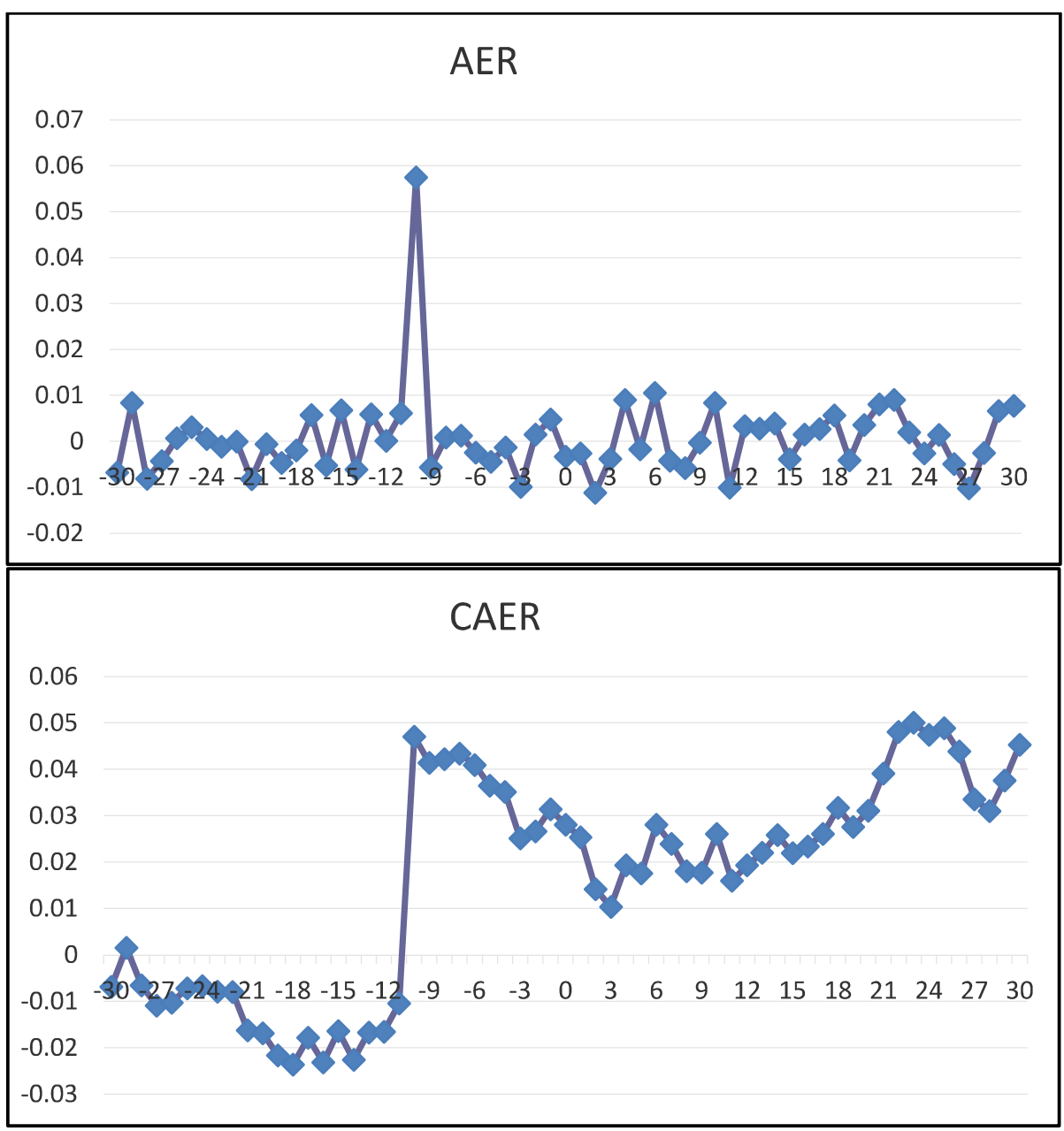


FIGURE 3

AER \& CAER OF 2016 SPONSORS

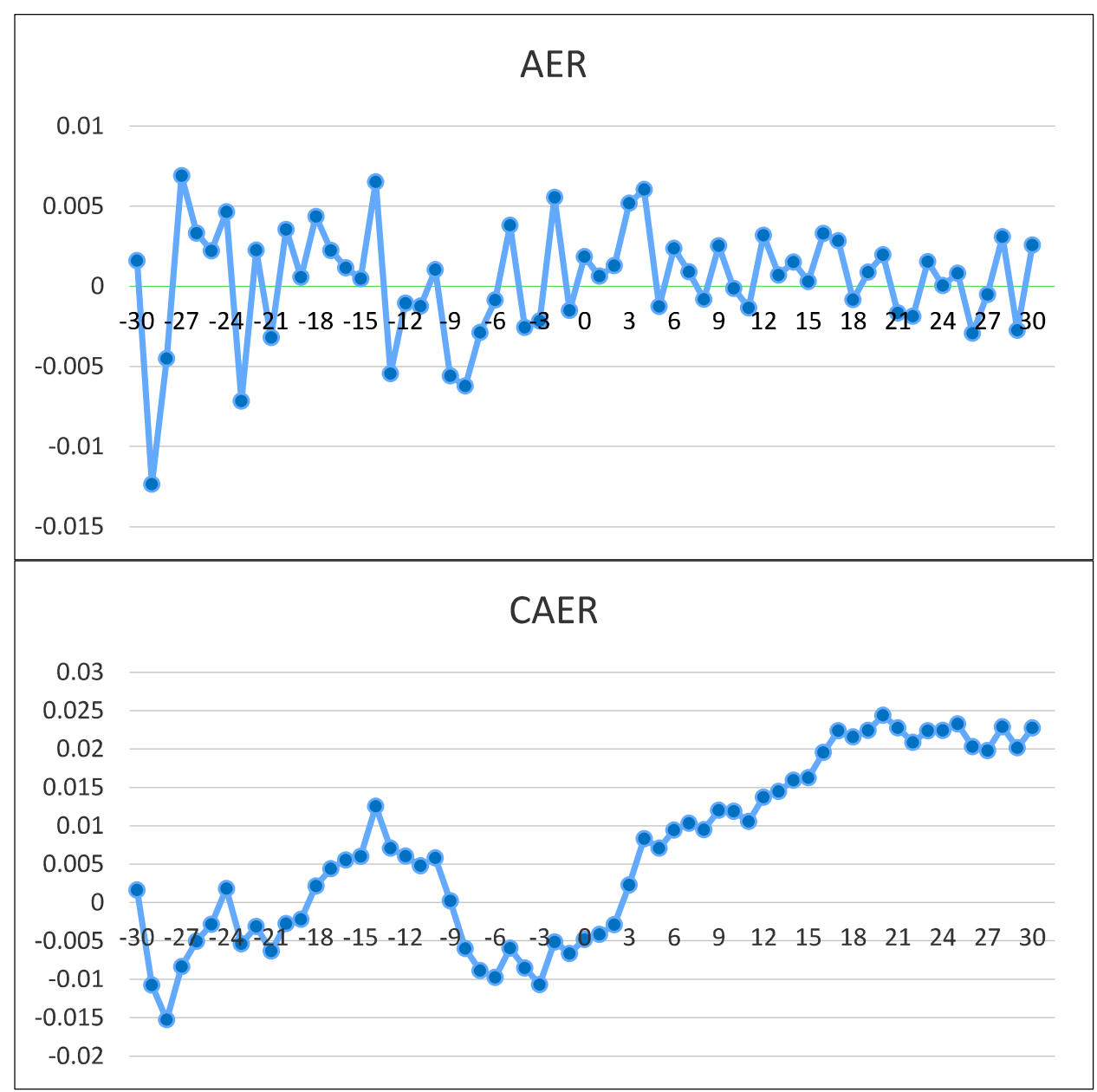

FIGURE 4

AER \& CAER OF 2008, 2012, 2016 (GLOBAL)

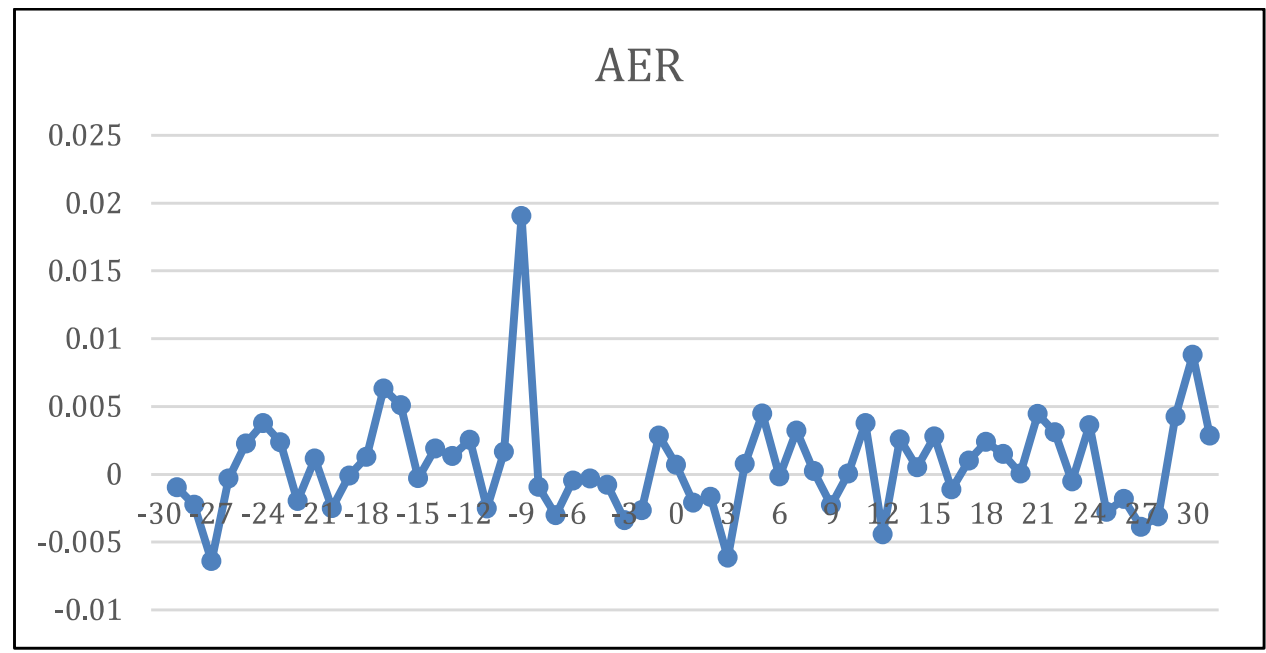




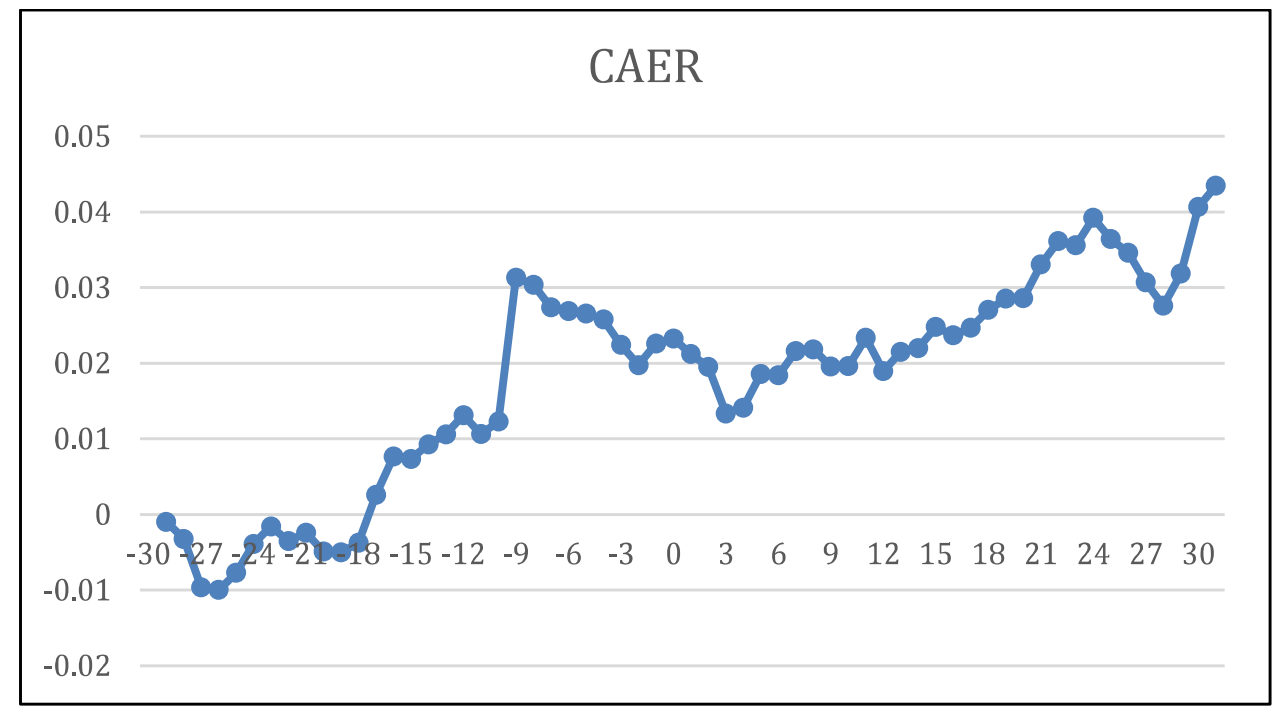

In summary, observation of CAER over the event period for all four samples support the null hypotheses $\mathrm{H1}_{0}, \mathbf{H 3}_{0}, \mathrm{H5}_{0}$, and $\mathrm{H} 7_{0}$ for the four samples, respectively: the risk adjusted rate of return of the stock price of the sample firms is not significantly positively affected by the opening ceremonies on August 8th, 2008, July 27th, 2012 and August 5th, 2016 on the event date as defined by the event period. Likewise, the observation evidence supports the alternate hypotheses $\mathbf{H 2}_{1}, \mathbf{H 4}_{1}, \mathbf{H 6}_{1}$, and $\mathrm{H8}_{\mathbf{1}}$ for the four samples, respectively: the risk adjusted rate of return of the stock price of the sample firms is significantly positively affected by the opening ceremonies on August 8th, 2008, July 27th, 2012 and August 5th, 2016 around the event date as defined by the event period. Figure 4 provides a global analysis of AER and CAER over the event period by combining all three samples to provide a more comprehensive examination with greater validity. Evidence here shows excess returns begin up to 27 days before day 0 with a gradual increase from the event date to day +30 . The global analysis effectively smooths the data over the event period and supports the results observed by the 3 individual samples. Overall, the global analysis of the opening ceremonies on August 8th, 2008, July 27th, 2012 and August 5th, 2016 supports the alternate hypotheses and confirms semi-strong form market efficiency.

\section{CONCLUSION}

The purpose of this event study was to test market efficiency and determine whether the 2008, 2012 and 2016 Summer Olympics Games had a positive risk adjusted rate of return for the stock prices of the 45 selected sponsor companies. Does the Olympic Games sponsorship investment decision increase or decrease stockholder wealth and the value of the firm? Evidence shows an increase in risk-adjusted returns for the stock prices of the sample firms up to 27 days prior to event date (day 0), but then staying constant for the duration of the Games. Therefore, evidence supports semi-strong form market efficiency since the market anticipated the gains and stock prices of the corporate sponsors of the Olympic Games reacted positively prior to the event date. No investor could earn an above normal return by acting on this information on the date of the opening ceremony (day 0). Evidence shows that the Olympic Games sponsorship investment decision increases stockholder wealth and the value of the firm. Thus, these results support the hypothesized positive effect on stock price return of the sponsorship investment. Results provide companies who are evaluating the Olympic Games sponsorship investment decisions more evidence, thus enabling them to better maximize stockholder wealth with positive net present value investment decisions. 


\section{REFERENCES}

Bacon, F.W., \& Cannon, C.C. (2018). Brexit Announcement: A Test of Market Efficiency. Journal of Applied Business and Economics, 20(8), 19-25.

Bacon, F.W., \& Gobran P. (2017). Presidential elections and industry stock returns: A test of market efficiency. Journal of Business and Behavioral Sciences, 29(2), 21-31.

Bacon, F.W., \& Greis, J. (2008). Stock split announcements: A test of market efficiency. Journal of Business and Behavioral Sciences, 18(1), 18-27.

Bacon, F.W., \& Spradlin, K.M. (2019). Forward and Reverse Stock Splits: A Test of Market Efficiency. Journal of Applied Business and Economics, 21(5), 18-28.

Bacon, F.W., \& Thompson, B. (2009). The 2008 Beijing Summer Olympics Effect on Its Sponsor Companies' Stock Prices. Proceedings of the Allied Academies International USA, 14(1), 50.

Baim, D.V., Goukasian, L., \& Misch, M.B. (2016). Olympic Sponsorships, Stock Prices, and Trading Activity. International Journal of Sport and Finance, 10(2) 175-195.

Beaver, W. (1981). Market Efficiency. The Accounting Review, 56(1), 23-37.

Clarey, C., Powell, M., \& Sandomir, R. (2016, August 22, 23, \& 26). Rio Olympics 2016. Retrieved from https://www.nytimes.com/news-event/rio-olympics-2016

Fama, E.F. (1965). The Behavior of Stock Market Prices. The Journal of Business, 38(1), 34-105.

Fama, E.F. (1970). Efficient Capital Markets: A Review of Theory and Empirical Work. The Journal of Finance, 25(2), 383-417

Fama, E.F. (1997). Market Efficiency, Long-Term Returns, and Behavioral Finance. Journal of Financial Economics, 49, 283-306.

Fama, E.F., \& Blume, M.E. (1966). Filter Rules and Stock-Market Trading. The Journal of Business, $39(1), 226-241$.

Finnerty, J. (1976). Insiders and Market Efficiency. The Journal of Finance, 31(4), 1141-1148.

Jensen, M.C. (1978). Some Anomalous Evidence Regarding Market Efficiency. Journal of Financial Economics, 6(2/3), 95-101.

Levy, R. (1966). Conceptual Foundations of Technical Analysis. Financial Analysts Journal, 22(4), 8389.

Levy, R.A. (1967). The Theory of Random Walks: A survey of Findings. American Economist, 11(2), 3448.

Mcnichols, M., \& Dravid, A. (1990). Stock Dividends, Stock Splits, and Signaling. The Journal of Finance, 45(3), 857-879.

O'Connell, M. (2016, August 6). TV Ratings: Rio Olympics Opening Ceremony Falls 28 Percent from London. The Hollywood Reporter. Retrieved from www.hollywoodreporter.com/live-feed/tvratings-rio-olympics-opening-ceremony-how-many-watched-917393

Ross, S.A., Westerfield, R., Jaffe, J., \& Jordan, B. (2016). Corporate Finance (10th ed.). McGraw-Hill Education.

Rozeff, M.S., \& Zaman, Z.A. (1988). Market Efficiency and Insider Trading: New Evidence. The Journal of Business, 61(1), 25-44. 